\title{
TRANSVERSUS ABDOMINIS PLANE (TAP) BLOCK WITH DIFFERENT BUPIVACAINE CONCENTRATIONS IN PAEDIATRIC PATIENTS UNDERGOING UNILATERAL INGUINAL HERNIA REPAIR SURGERY: \\ A PROSPECTIVE RANDOMISED \\ DOUBLE-BLINDED STUDY
}

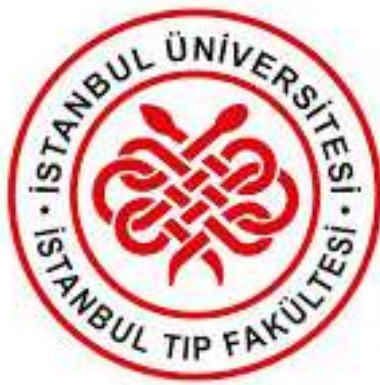

\author{
M SAVRAN-KARADENIZ, EA SALVIZ, B DINCER, \\ H SENTURK-CIFTCI, KM TUGRUL, M ORHAN-SUNGUR \\ ISTANBUL UNIVERSITY, MEDICAL FACULTY OF ISTANBUL, DEPARTMENT OF ANAESTHESIA
}

Background: Transversus abdominis plane (TAP) block is a safe and effective analgesia technique for paediatric patients (1). This study is designed to compare the analgesic efficacy of different bupivacaine concentrations in paediatric patients undergoing ultrasound-guided TAP blocks for unilateral inguinal hernia repair surgery.

Materials and Methods: Seventy-four patients aging between 1 and 8 years, undergoing unilateral inguinal hernia surgery, were enrolled for this study after obtaining Institutional Ethics Committee approval and written informed consents from parents or legal guardians (2016/1281). Group 1 (n:37) received $1 \mathrm{mg} / \mathrm{kg}$ bupivakain $0.25 \%$ and Group 2 (n: 37) received $1 \mathrm{mg} / \mathrm{kg}$ bupivakain $0.125 \%$ for ultrasound-guided TAP block following standard general anaesthesia induction (Figure 1). All patients received remifentanil $0,1 \mu \mathrm{g} / \mathrm{kg} / \mathrm{h}$ infusion and paracetamol $15 \mathrm{mg} / \mathrm{kg}$ intraoperatively, and paracetamol 4x15 mg/kg per day postoperatively. FLACC (Face, Legs, Activity, Cry, Consolability) behavioral pain assessment scale was used for evaluating patients' postoperative pain levels at 15-, 30-, 45-minute and 1-, 2-, 6-, 24-hour. Tramadol 1 $\mathrm{mg} / \mathrm{kg}$ was administered intravenously as rescue analgesic when FLACC score was $\geq 4$. Total analgesic requirement, length of hospital stay and side effects were recorded.

Results: Sixty-four patients, Group 1 (n:30) and Group 2 (n:34), completed the study. Demographic data were similar in both groups $(\mathrm{p}>0.05)$. FLACC pain scores at all time points (Figure 2), total analgesic requirement and length of hospital stay were all comparable in both groups $(\mathrm{p}>0.05)$.

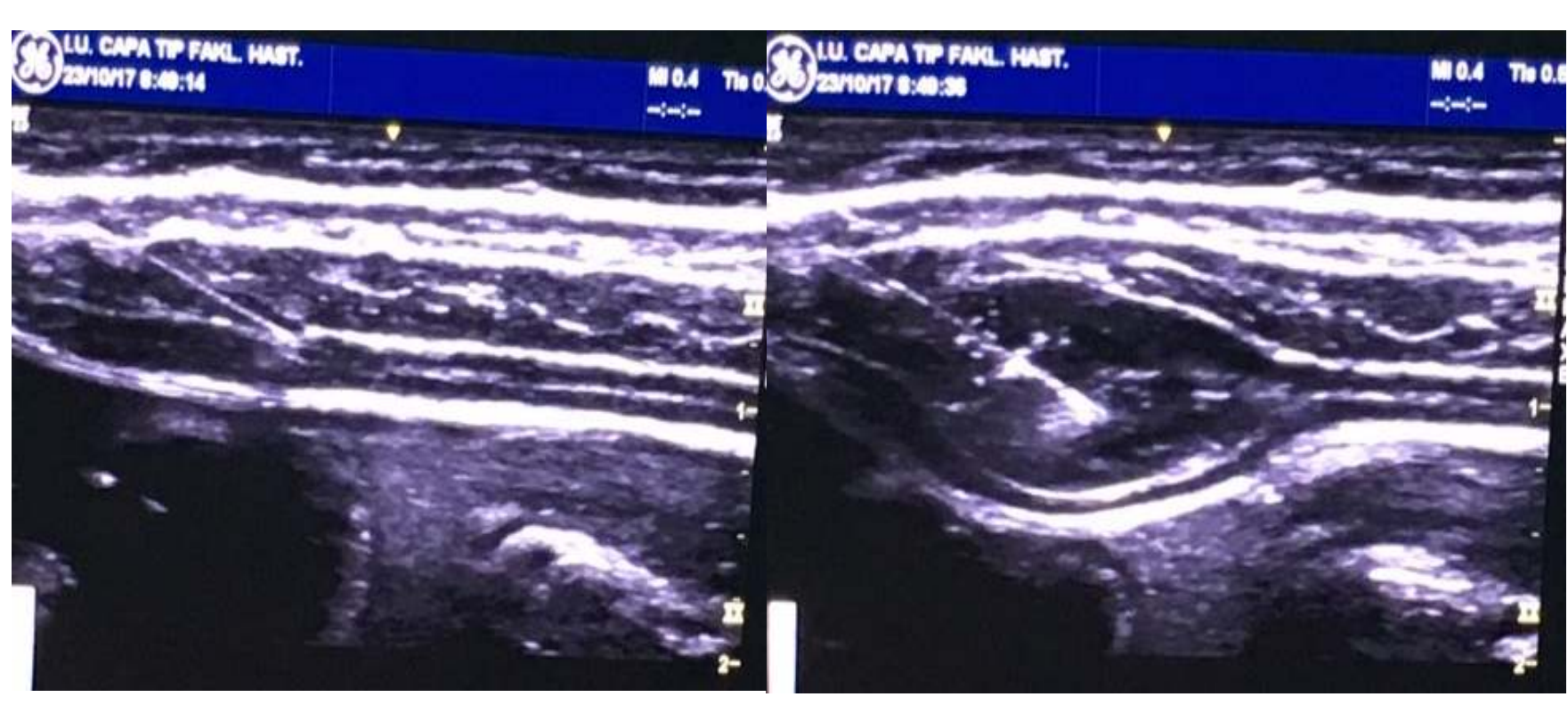

Figure 1: The performance of ultrasound-guided TAP block

None of the patients reported FLACC score $\geq 4$ or asked for rescue analgesic after postoperative $6^{\text {th }}$ hour. No perioperative and/or postoperative complication was observed.

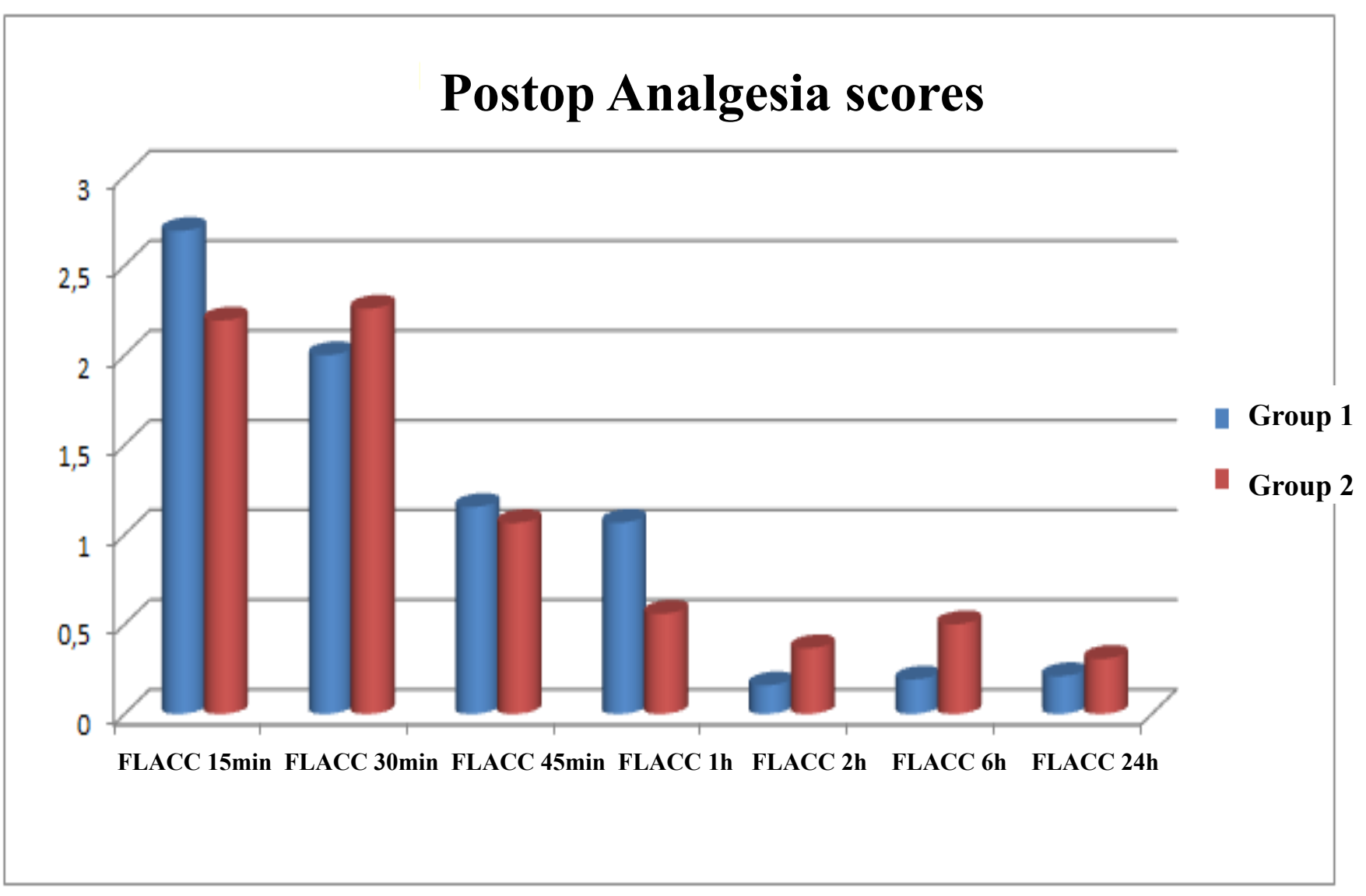

Figure 2: FLACC scores of patients through the postoperative first 24 hours

Conclusion: This study demonstrated that higher and lower concentrations of bupivacaine do not have any superiority over each other when the doses are kept equal in TAP blocks. TAP blocks are effective regional analgesic techniques for pediatric patients undergoing inguinal hernia repair surgery. 